\title{
Investigating the impact of the use of security equipment in the confrontation with the arrival of alcoholic drinks "Case Study of Ghorveh City"
}

\author{
Reza Mohammadi ${ }^{1}$ \\ Seyyed Sajjad Kazemi ${ }^{2}$
}

\author{
1 Department of Law, Hamadan Branch, Islamic Azad University, Hamadan, Iran \\ E-mail: rezamohammadi@gmail.com \\ 2 Assistant Professor, Malayer University, Malayer, Iran. \\ E-mail: sskazemi92@malayeru.ac.ir
}

\begin{abstract}
The subject of the present study is to investigate the effect of the use of law enforcement equipment on the criminal response to the arrival of alcoholic beverages in the city of Ghorveh. This research has been conducted with a quantitative and survey approach and a researcher-made questionnaire. The statistical population of the study consisted of 20 expert police officers, responsible and knowledgeable in the subject of the city of Ghorveh and all of them were tried to complete the questionnaire. Validity and reliability of the research tool (questionnaire) were determined through face validity and Cronbach's alpha test using Spss software. In describing the research fields, the results showed that most respondents were distributed in the "large" and "very large" spectrum. In other words, the majority of respondents believed that the use of appropriate security equipment to counteract the smuggling of alcoholic beverages in Qorveh city has been effective in preventing this issue. According to the results of this research, the use of appropriate equipment to fight smuggling of alcoholic beverages in the country as a whole, and in particular in the city of Ghorveh, is extremely effective and effective. According to respondents, the use of modern and new car equipment (With an average response of 4.85 points) As well as the use of databases (With an average response of 4.65 points) In Ghorveh, the city has the most impact on the fight against smuggling of alcoholic beverages.

Keywords: law enforcement, smuggling, alcoholic beverages
\end{abstract}

\section{Introduction}

One of the ways in which it was able to fight and deal with the smuggling of illegal goods and the illegal and illegal entry of smuggled and forbidden goods into and through the borders of the country, is physical confrontation, investigation into the crime of smuggling and arresting offenders, inspection, and other acts which is one of the duties of the law enforcement force as the judiciary. The duties of the police force in accordance with Article 4-8 include the following (Madani and Moghimi, 2018).
Table 1: Tasks of the Police in accordance with Article 4-8

\begin{tabular}{|l|l|l|}
\hline $\begin{array}{l}\text { 1) Counter } \\
\text { Narcotics }\end{array}$ & $\begin{array}{l}\text { 4) Crime Preven- } \\
\text { tion }\end{array}$ & $\begin{array}{l}\text { 7) Maintaining works } \\
\text { and reasons for crime } \\
\text { and studying them }\end{array}$ \\
\hline $\begin{array}{l}\text { 2) Combating } \\
\text { smuggling }\end{array}$ & $\begin{array}{l}\text { 5) Discovery of } \\
\text { crime }\end{array}$ & $\begin{array}{l}\text { 8. Arresting the ac- } \\
\text { cused and the perpetra- } \\
\text { tors and preventing } \\
\text { them from escaping } \\
\text { and hiding them }\end{array}$ \\
\hline $\begin{array}{l}\text { 3) Fighting vices } \\
\text { and corruption }\end{array}$ & $\begin{array}{l}\text { 6) Perform } \\
\text { inspection and } \\
\text { investigation }\end{array}$ & $\begin{array}{l}\text { 9) Implementing and } \\
\text { communicating judicial } \\
\text { rulings. }\end{array}$ \\
\hline
\end{tabular}

According to the second paragraph of this article, one of the most important duties of the police is the fight against smuggling and alcoholic beverages are one of the things that are imported and distributed through smuggling. This task is carried out by the deputy of 
this organization and of course, it should be noted that countering smuggling of alcoholic beverages is impossible by military and law enforcement agencies. Except by providing financial resources and equipping the necessary technical and human resources and motivating them with the encouragement and encouragement of forces and the necessary and strict monitoring of the borders and the use of trained military forces is of great importance and the use of the latest scientific and technical tools and techniques to identify criminals and delinquents and methods of detecting crimes, psychology, prosecution of arrests of criminals, etc., is also necessary.

\section{Literature Review}

Smuggling: In the definition given by the World Customs Organization on smuggling and accepted by its members, including Iran, it is stated that: "Smuggling is a customs offense involving the movement of goods along a customs border by secret means and in order to escape customs supervision" (Ahmadi, 2004).

Smuggling: In the eyes of the economy, any kind of goods that are secretly imported into and out of the country are also known as smuggling goods. In fact, transporting goods from one point to another, whether there are two points inside the country, in which case domestic trafficking and whether there is a point inside and outside the outside that they are talking about foreign smuggling (Langrody, 2007).

Alcoholic drinks: whatever that its material be drunk. (Ashrafi 2007) Smuggling of alcoholic beverages is of a hidden and imported kind. Alcoholic beverages are prohibited goods and their sale are illegal and prohibited according to the Islamic Penal Code, the importer of alcoholic beverages will be punished for 6 months to 5 years imprisonment and 74 lashes and cash payments equal to ten times the customary value of the goods (TASNIM News, 2016).

Alcohol smuggling methods: According to the study, a large amount of alcoholic beverages imported by Iranians to the border $(80 \%)$ Borderlands enter the country with horse or foot through the impossible mountainous routes, importing alcoholic beverages from Iraqi Kurdistan and the rest by entering in fuel tanks and ... through official holidays (Salmani, 2017).

Causes of Drug smuggling: High profitability against low risk, geopolitics (The breadth of the boundaries and the mountainousness of the western borders and the desertification of the eastern borders), Cultural poverty, the degree of blame for criminal behavior (Low smuggling), Obligation to observe tribal norms, economic poverty and unemployment (Salmani, 2017).

Consequences of Smuggling: Drug addiction is one of the biggest social and social consequences for the individual, family and society alcohol consumption affects the body, mind, work, social relationships and community culture (Salmani, 2017).

Police Manager: Police Department of Science and Arts use all material and spiritual resources of the police in order to plan, organize, direct and supervise and supervise and control, to achieve organizational goals that are to establish and maintain order, security and peace in society (Mostafa Nejad, 2010).

Security management practices: Management practices are summarized in two processes of prediction and prevention; Anticipation of the occurrence of irregularities (crime or crisis) and creating organizational readiness is one of the most important duties of law enforcement. Social prevention involves eliminating or defusing effective factors in the development of crime in society and in the context of precautionary measures, measures are in place to reduce the opportunities and 
circumstances of committing crime and make matters worse off (Salmani, 2017).

\section{Law enforcement strategies aga- inst smuggling}

A) Forecast strategy: Set of measures, plans and actions of the police and agents involved in the fight against smuggling

B) Prevention strategy: All measures taken to prevent smuggling and facilitation, such as reforming the rules, structural reforms, supplying goods from official channels, organizing border exchanges, providing livelihoods and goods for the border residents, and ...

C) Control strategy: Supporting and tracking the management of the borders of the water, land and air, in order to prevent the entry of smuggled goods by strengthening and equipping law enforcement forces along the water and land borders, customs supervision on all border transactions, coordinated management on all official bases.

D) Coping strategy: Adaptation and exchange of punishment methods for perpetrators and stewards of smuggling, strengthening intelligence efforts to discover the main networks and agents of smuggling, to plan continuously, and to prepare antismuggling countermeasures.

E) Restoration and reconstruction strategy: Promoting employee morale, anticipating further measures and measures of smugglers to prevent similar cases, increasing trust in the police, identifying storage sites and designing successful and successful operations.

\section{Research hypotheses}

Police management practices based on prediction, prevention, control, coping and restoration and over-moderation to counter- act the smuggling of alcoholic beverages in the city of Ghorveh.

\section{Research background}

In recent years, many studies have been conducted on the causes and factors affecting smuggling of goods, the consequences of smuggling and the prevention of smuggling of goods. Since the present research has used theoretical considerations and a method of research, at first some of them are mentioned.

In the following, it is referred to research that focuses on law enforcement practices, however, the issue or issue they are considering is not smuggling alcohol. In any case, it is important to note that: with the exploration of literature and research documents, no investigation was found on the "Law Enforcement Practices for fighting smuggling of alcoholic beverages". Therefore, the present research is an anecdotal point of view and even a place.

\section{Investigations related to smug- gling goods:}

Yousefvand and Khani, in a paper titled "Reviewing the Prevention Strategies for Trafficking in Goods with a Regulatory Approach" conducted by descriptive-survey method among 131 managers and experts in the field of smuggling of goods, it was concluded that among the five preventive strategies, the reduction of predictable smuggling benefits with the highest score was the most appropriate response from respondents. In the ranking of all the subcommittees, the fast and decisive approach to the main areas of smuggling has been the highest among respondents. The present research has used some of the indicators of law enforcement in this study (Yousefvand and Khani, 2013).

Aslani Slamser, in an article devoted to social factors affecting the orientation of the 
borderland, was aimed at smuggling goods (areas and solutions). The research method was a questionnaire survey with interviews. The statistical population of this study was borderline labor traffickers in Baneh and in 2014 an interview was conducted with 381 of them (colbran, marketers and smugglers) who were selected in a disproportionate, targeted, and accessible and snowball manner. In a nutshell, they concluded that high structural pressures are associated with increased smuggling and high social commitment by reducing the adoption of smuggling. Also, there is an inverse relationship between age and smuggling, and there is a direct relationship between education and trafficking. The researchers have proposed the creation of free trade-industrial zones and the fair distribution of business cards between Colbaran as vulnerable populations as the most important ways to prevent smuggling of goods (Aslani Slamser, 2015).

Abdolmohammadi studied social factors affecting smuggling in Iran, Based on the results of the research, he has offered suggestions in the field of economic, social, cultural, political and law enforcement (Abdulmohammadi, 2009).

Mohseni Tabrizi and his colleagues in an article entitled "Factors Influencing the Smuggling of Arms and Alcoholic Beverages from the Pyrshshir District" The survey method and the application of the questionnaire technique used to collect the information needed to examine the relationship between the independent and dependent variables of 124 heads of households living in the city and 30 commanders and senior officers of the police force of the Piranshahr area. Based on the results of the research, they have presented valuable suggestions that could be a guide for the research (Mohseni Tabrizi, 2008).

In his dissertation, Ashrafi reviewed the "Practical Practices to Counteract Smuggling of Alcoholic Goods and Sardasht Borders in
2006". Research methodology in this library study, field survey and survey data was collected from 70 operational personnel of Sardasht city. In his study, the researcher concluded that the collection of information across borders and the use of investigation and interrogation of the defendants as well as the use of resources, neglected, subtle research and change of traffickers' care in dealing with smuggling are the most effective way to deal with smuggling of liquor in this region (Ashrafi, 2007).

\section{Research related to law enforce- ment practices:}

Yavari and Besharati, in their research, they examined the effectiveness of law enforcement in the unrest in the 9th Islamic Consultative Assembly in the district police department of Dorood. The research method was survey, survey and statistical community, law enforcement experts, political and security related to the issue of elections in the center of Lorestan province (Khorram Abad) and Dorood city. They found in their research that: The effectiveness of NAJA management in unrest in terms of performance was better in the stage of prediction, recovery and rehabilitation, prevention and prevention and this confirms that the police have been more successful in discussing prediction and recovery, and have been in the process of coping and preventing them in the traditional way. New methods and techniques, including psychological operations, have not functioned well on the basis of emotion drainage operations, population segregation operations and time management and need to plan and improve systemic abilities and some kind of addictive skill. The present research in theoretical discussions and in creating some of the indicators of law enforcement management has benefited from this study (Yavari and Besharati 2014). 
Vatankhah, in his study, he examined the pattern of law enforcement in preventing guilty objections. The research method was then a survey-type event the sample of 20 police stations and 9 senior police stations were randomly selected among the police stations of Tehran. In his study, the researcher concluded that the lack of intervention of antitrust units in most cases and the use of police-negotiating techniques to prevent the spread of protests, the presence of police officers on the scene from the beginning of the protests to the end, Failure to deal violently with protesters can be an effective factor in policing. In summary, the results of this research show that, contrary to the general perception of NAJA staff managers, the great Tehran militias have had a great influence in the stages of anticipation and prevention of guilty objections (Vatankhah, 2013).

Moayedi in an article analyzes and criticizes the pattern of coping with the supply and sale of narcotics. The researcher in this article argues that counter narcotics has two approaches to supply and demand reduction. Deal with supply is done with using intelligence and martial law enforcement. In other words, it means countering the supply of measures such as stopping the arrival, smuggling and distribution of materials, which has a legal and informational nature. Law enforcement measures against supply in the country are also carried out and the Counter Narcotics Policies view includes enforcement measures to deal with the cultivation and production of narcotics, dealing with entry, transportation and dealing with distribution. In the end, the researcher concludes that the implementation of countermeasures with supply has a direct impact on the risk of drug supply. Also, the police pattern alone is not responsive to the supply of drugs and the counter-narcotics strategy must be a system strategy, that is, all of its dimensions and elements should be considered (Mayedi, 2015).
Asgari in an article explores the role of law enforcement in controlling the hijab phenomenon in the region of Tehran. The research, survey and statistical sample consisted of 84 employees of ethical security staff, experts and elite of NAJA Public Information and Security Police, the research data were collected using a questionnaire. The researcher concluded in his study that the impact of peaceful measures (Cultural and educational approach including public education, information, encouragement and encouragement, cooperation in fashion and clothing exhibitions) In controlling the hijab phenomenon more than compulsory measures (Coping actions and activities including reminder, justification, commitment, arrest, introduction to the judicial authority, etc.) And therefore, it has proposed peaceful measures to control bad guys (Asgari, 2014).

At the end of this section, it is reiterated that despite the fact that in recent years, many studies have been conducted in the area of smuggling of goods or law enforcement practices in dealing with various issues, but research in the field of law enforcement practices dealing with the smuggling of alcoholic beverages, especially in Ghorveh city of Kurdistan province, is a new issue. Nevertheless, in the present research, theoretical achievements and the experimental research method are used to achieve the goal.

\section{Research methodology}

The method of doing this research is quantitative and using random sampling. In quantitative research, there are a variety of sampling practices that are likely to be the main basis and the most important feature of it is the particular chance for each person to be elected or absent sampling is done randomly and all efforts of the researcher are to prevent prejudices. By doing so, it is expected that the closest value will be estimated relative to the 
parameter of the community from which the sample is selected. Here, sampling is done randomly, the survey data were collected by a questionnaire and then evaluated and analyzed. In evaluating and analyzing information, the results of such methods as improvement methods, number, accuracy and quality of responses are effective. The aim of this study was to collect data using a questionnaire identifying the effective equipment of law enforcement to deal with the entry of alcoholic beverages in Ghorveh city.

In a more general view of the research, it can be said that the present study is a quantitative research in terms of approach to the subject and issue, and is descriptive in nature as a surveying method. This research is applied in terms of purpose, research and application in order to provide practical solutions to combat the entry of alcoholic beverages in the city of Qorveh. Data gathering tool in this research is a researcher-made questionnaire with closed questions and with definite answers. A good test should have desirable features such as objectivity, ease of implementation, practicality, ease of interpretation and interpretation, validity and reliability to lead to correct results; for this purpose, its validity and reliability have been investigated. The validity of the tool was confirmed by referring to the theoretical and faculty professors and the reliability of the tool through Cronbach's alpha test.

The statistical community refers to the set of individuals, objects, or in general phenomena that the researcher can generalize to the outcome of their study. The statistical population of the research is identified by one or more common attributes. In most cases, due to the large size of the statistical community, it is not possible to refer to all of the community and study them individually. In this case, the researcher has to study a part of the statistical society and generalize the outcome of the survey to the entire statistical community. Re- ferring to a section of the statistical community to identify all of them is called sampling method. It is possible to do this when it is possible to sample a part of all the characteristics and characteristics of the statistical community and can be viewed as a community display. So the statistical sample refers to a part of the statistical society that has the characteristics and characteristics of the statistical society in itself and the researcher can judge with the study of that section about the statistical society. At the same time, the statistical sample should be accessible and available to the researcher. So that it is clear about the statistical sample and can be used for the statistical sample of two major features of validity and volumetric proportions. Validity of the statistical sample is that we can consider the sample as a part of the statistical society in terms of its similarity to the studied population and possessing its features and attributes. The proportional volume of the sample is that the study section has a sufficient and adequate volume, so, in quantitative terms it can be viewed as a representation of the statistical society and generalized the results of the study to the society (Ranjbar et al., 2012).

In this research, the statistical population consisted of employees of the police department of Qorveh city which randomly distributed questionnaires between a numbers of them. In fact, the statistical community of the study is among the officers (15\%), component officers (65\%), senior officers (15\%) and other employees $(5 \%)$ of the police force in the city of Ghorve, and their number are twenty. The respondents were in the questionnaire with a diploma (25\%), an undergraduate degree $(20 \%)$, a bachelor's degree (35\%) and a master's degree (20\%). In this research, the statistical population of the respondents was tested for a variety of years of service; Therefore, the questionnaire respondents included collaborators whose service ranges ranged from 0 to 5 years $(15 \%), 5$ to 10 years $(10 \%)$, 
10 to 15 years $(25 \%), 15$ to 20 years $(25 \%)$, and more than 20 years $(25 \%)$.

\section{Results}

When a bunch of little information is gathered for research, first, it is necessary to organize and summarize them in a way that is meaningfully understandable and relevant. Descriptive statistics methods are used for this purpose. Often the most useful and, at the same time, the first step in the data organization is to sort the data based on a logical criterion and then extracting the central indexes and dispersion and, if necessary, calculate the correlation between the two categories of information and the use of more advanced analyzes such as regression. In a compilation, descriptive statistics methods can be used to accurately describe the characteristics of a bunch of information. Descriptive statistics are always used to determine the characteristics of research information.

In this research, one of the issues that we have included in the questionnaire and influences the use of alcoholic beverages in law enforcement practices is the equipment sector used by the police. The fourteen questions that were raised in this questionnaire and each of the colleagues answered this part of the question and found interesting results.

As we said, in this research, reliability of the questionnaire was measured by Cronbach's alphabet test and for this purpose, the SPSS software was used and related questions related to the smuggling of alcoholic beverages and the Cronbach's alpha coefficient was 0.858 , It was found that this section of the questions has a satisfactory reliability (0.858>0.7).

Descriptive statistics are a set of methods used for organizing, summarizing, preparing tables, plotting, describing and interpreting data collected from a statistical sample. A statistical dataset consists of a set of values of one or more variables. Therefore, descriptive statistics include the section of statistics that relates to the characteristics and statistics of the statistical sample of research. The role of descriptive statistics in the process of statistical analysis is crucial. Descriptive statistics, by summarizing the data, reveal their important features in order to create the necessary ideas in the minds of the researcher for the second stage of statistical analysis (inferential statistics).

We used the following formulas to calculate the mean, variance, and standard deviation of the following formulas.

Average formula:

$\bar{x}=\frac{1}{n}\left(\sum_{i=1}^{n} x_{i}\right)=\frac{x_{1}+x_{2}+\cdots+x_{n}}{n}$

Variance formula:

$S_{n}^{2}=\frac{1}{n} \sum_{i=1}^{n}\left(x_{i}-\bar{x}\right)^{2}$

SD formula:

$S=\sqrt{S_{n}^{2}}=\sqrt{\frac{1}{n} \sum_{i=1}^{n}\left(x_{i}-\bar{x}\right)^{2}}$

The questionnaire for the fight against alcohol smuggling questioned the questionnaire separately, the mean of response and variance and its standard deviation (Table 2). 
Table 2: Average total score of respondents to questions related to equipment section of the questionnaire with mean, variance, standard deviation and total regression

\begin{tabular}{|l|l|}
\hline Average score of all respondents & Question number \\
\hline 4.65 & Qt1 \\
\hline 4.65 & Qt2 \\
\hline 4.5 & Qt3 \\
\hline 4.1 & Qt4 \\
\hline 4.45 & Qt5 \\
\hline 4.85 & Qt6 \\
\hline 3.9 & Qt7 \\
\hline 4.3 & Qt8 \\
\hline 4.15 & Qt9 \\
\hline 4.4 & Qt10 \\
\hline 4.55 & Qt11 \\
\hline 4.05 & Qt12 \\
\hline 4.45 & Qt13 \\
\hline 4 & Qt14 \\
\hline 4.357142857 & $\overline{\boldsymbol{x}}$ Average( \\
\hline 0.07956044 & S $\left.^{2}\right)$ Variance( \\
\hline 0.282064602 & S) SD( \\
\hline 0.1936 & $\left.\mathrm{R}^{2}\right)$ regression( \\
\hline & \\
\hline
\end{tabular}

Graph 1: Frequency distribution and frequency of subjects related to the use of databases (Qt1)

\begin{tabular}{|c|}
\hline Question-related equipment $\mathbf{Q}_{\mathrm{t} 1}$ \\
\\
\end{tabular}

In the area of fighting smuggling of alcoholic beverages, According to respondents, the use of databases is significant and very high (with an average response of 4.65 points) in countering smuggling of alcoholic beverages.
Ghraph 2: Frequency charts and frequencies related to the use of the GPS system (Qt2)

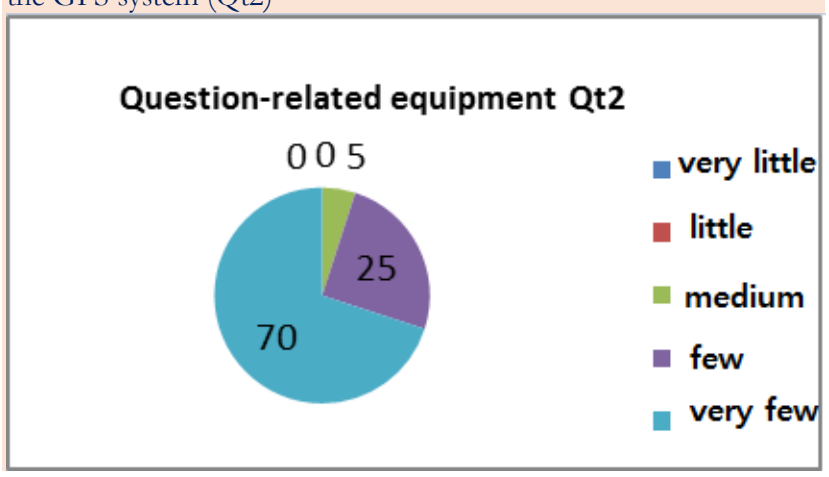

According to respondents, the use of the GPS system is significant and very high (with an average response of 4.65 points) in countering smuggling of alcoholic beverages.

Graph 3: Frequency charts and frequencies related to subjects;

Using the $\mathrm{x}$ ray device (Qt3)

\section{Question-related equipment} Qt3

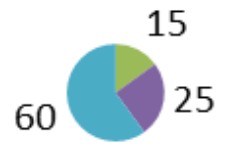

very little

- little

medium

According to respondents, the use of the $\mathrm{x}$ ray device is very effective (with an average response of 4.50 points) in countering smuggling of alcoholic beverages.

Graph 4: Frequency charts and percentage of subjects involved; use of Geographic Information System (Qt4)

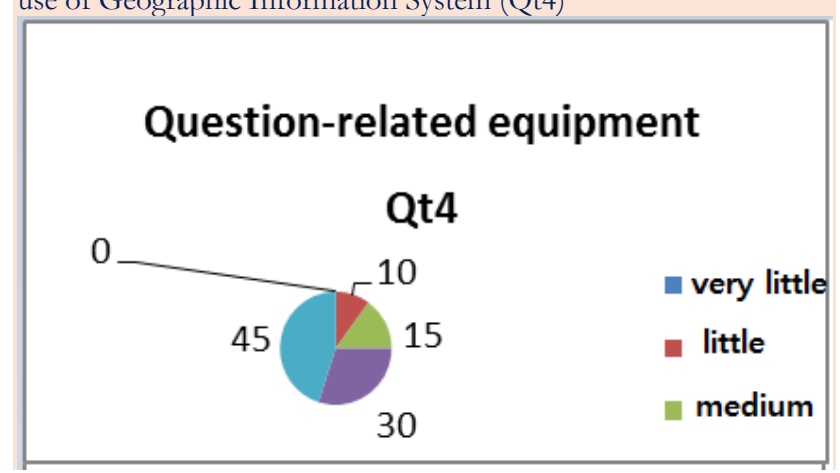

According to respondents, the use of the GIS system is very effective (with an average https://periodicos.unifap.br/index.php/estacao Macapá, v. 9, n. 1, p. 119-132, Jan./Mar. 2019 
response of 4.1 points) in counteracting smuggling of alcoholic beverages.

Graph 5: Frequency distribution and frequency of subjects related to; use of information sources and contributors (Qt5)

\section{Question-related equipment}
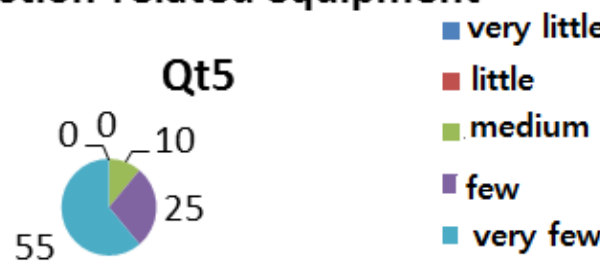

According to respondents, the use of information and information resources of contributors is very effective (with an average response of 4.45 points) in countering smuggling of alcoholic beverages.

Graph 6: Frequency charts and frequencies related to the use of modern and new car equipment (Qt6)

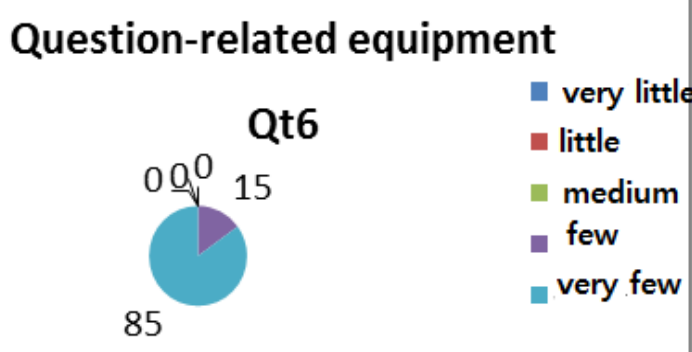

According to respondents, the use of modern and new car equipment is significantly and significantly affected (with an average response of 4.85 points) in countering smuggling of alcohol.
Graph 7: Frequency charts and frequencies related to the use of fixed (permanent) checkpoints (Qt7)

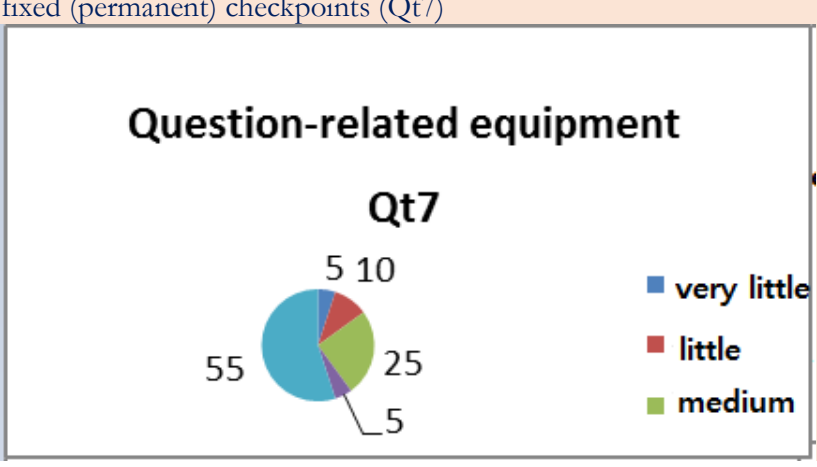

According to respondents, the impact of the use of permanent (permanent) checkpoints on dealing with smuggling of alcoholic beverages is high (with an average response of 3.9 points).

Chart 8: Frequency charts and frequencies of subjects related to; use of temporary checkpoints $(\mathrm{Qt} 8)$

\section{Question-related equipment Qt8}

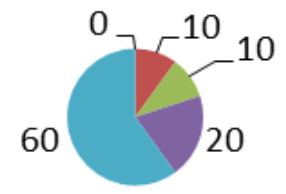

$$
\begin{aligned}
& \text { very little } \\
& \text { - little } \\
& \text { medium } \\
& \text { few }
\end{aligned}
$$

Based on respondents' responses, the impact of the use of temporary checkpoints on countering smuggling of alcoholic beverages is high (with an average response of 4.3 points).

Graph 9: Frequency charts and percentage of subjects involved; Formulation of Annual Planning for Fighting Execution Units $(\mathrm{Q} \mathrm{t} 9)$

\section{Question-related equipment Qt9}

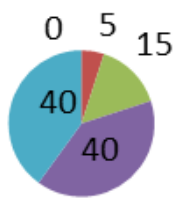

very little

n little

medium

few 
Based on respondents' responses, the annual planning for combat enforcement units is highly influential (with an average response of 4.15 points) in counteracting smuggling of alcoholic beverages.

Graph 10: Frequency and frequency distribution of subjects related to; Staff trainee guidance in trafficking cases (Qt10)

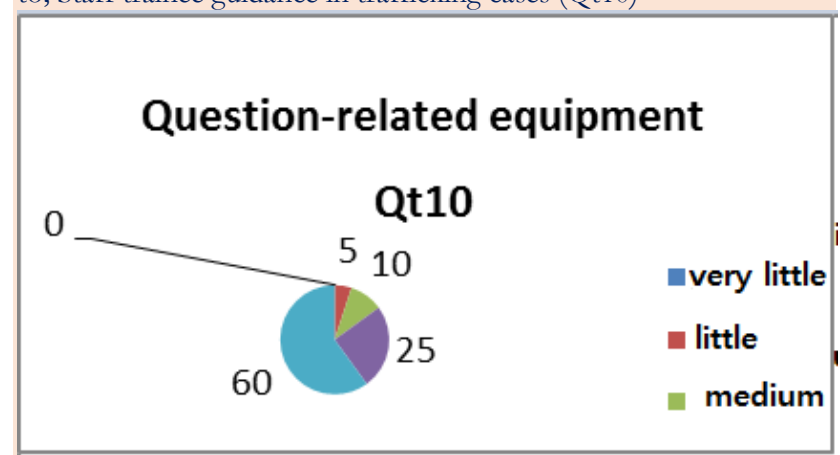

Based on the respondents' responses, the effectiveness of staffing guidance in smuggling cases in dealing with smuggling of alcoholic beverages is high (with an average response of 4.40 points).

Graph 11: Frequency charts and frequency of subjects related; developing a style sheet for smugglers to executive units (Qt11)

\section{Question-related equipment}

\section{Qt11}

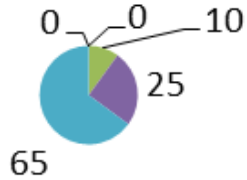

very little

- little

medium

Based on respondents' responses, writing a style sheet for smugglers into executive units is very effective (with an average response of 4.55 points) in counteracting smuggling of alcoholic. According to respondents, the effectiveness of the preparation of antismuggling guidelines in dealing with smuggling of alcoholic beverages is very high (with an average response of 4.05 points).
Graph 12: Frequency distribution and frequency of subjects related to; Preparation of anti-smuggling guidelines (Qt12)

\section{Question-related equipment Qt12

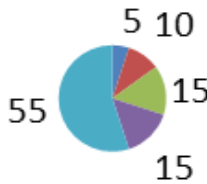 \\ very little \\ - little \\ medium}

According to the respondents, it was found that the preparation of anti-smuggling guidelines was very effective (with an average of 4.05 points) in counteracting smuggling of alcoholic beverages.

Graph 13: Frequency distribution and frequency of subjects related to the implementation of operational plans against the smuggling organization (Qt13)

Question-related equipment Qt13

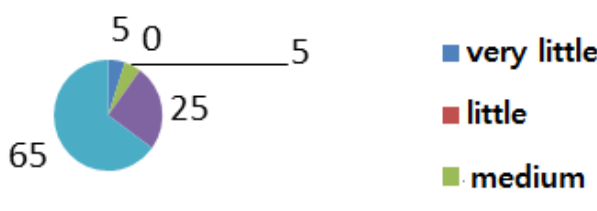

According to respondents, the implementation of operational plans against the smuggling organization is very effective (with an average response of 4.45 points) in countering smuggling of alcoholic.

Graph 14: Frequency charts and percentage of frequency of subjects; use of office automation system instead of correspondence (Qt14)

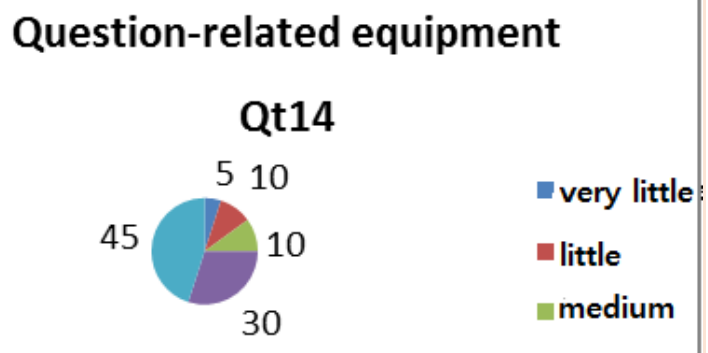


According to respondents, the use of the office automation system instead of correspondence is to expedite the delivery of plans, guidelines, staff guidance, practices and practices, breaking news of smuggling of liquor and ... From upper grades and vice versa, it is very effective (with an average response of 4.00 points) in countering smuggling of alcoholic beverages.

\section{Conclusion}

In the process of research, discussion and conclusion are important, because discussions and conclusions can be the basis for solving existing problems or improving the status quo towards the desired situation.

Trafficking in alcoholic beverages has a negative impact on the economic security of the community and will increase economic security by increasing legal and regulatory costs. This can increase the unemployment rate in society, it can also increase poverty and class distances in society, secure investment in society and in general, the country's economy is affected. Establishing institutions to fight smuggling, especially smuggling of alcoholic, costs a lot, and there are huge sums of money this year. Trafficking in prohibited goods, such as alcoholic beverages, and ... affects security and by creating a false job, it destroys society. Trafficking in alcoholic beverages is profitable, false and illegitimate, and traffickers thus gain a huge and windfall wealth and others are also affected by poverty and poverty as a result of such illicit trafficking. Therefore, under the influence of smuggling prohibited goods such as alcohol, poverty, unemployment and class distances are created.

Drug trafficking also has a negative social impact. The smuggling of these substances also increases the risk of violence and affects social security. Drug trafficking is a crime that is itself the cause of many other crimes.
Crossing unauthorized borders, carrying arms and committing murder and crimes for the preservation and successful transfer of alcoholic beverages, money laundering, theft, terror and arson by armed smugglers ... One of the examples of these crimes is that, along with their occurrence, the security and security of citizens is heavily affected. The smuggling of alcoholic beverages and other prohibited goods, in particular by disturbing the security of the affected areas, prevents equilibrium and equitable distribution of facilities and capabilities across the country and causes injustice in the distribution of facilities.

Drinking and smuggling also influences the cultural and moral dimension of society, it also negatively affects society's security. Trafficking in alcoholic beverages may have a negative impact on human development and quality of life and challenge the cultural values of society; this is contradictory to the Islamic beliefs of society and it is not illegal and illegitimate within the limits of the religious laws and customs of Iranian society. Considering the above and because of social issues such as unemployment, cultural invasion, class temperance, etc. This affects most young people and young people and with their tendency toward these materials, the most valuable assets and resources of the country for development, are virtually eliminated. These people are affected by the smuggling of prohibited goods, including alcoholic beverages and gradually lose their identity and ultimately challenge the security of society.

Alcoholic beverages are among the goods that smuggle into the general interests of society. In fact, smuggling of alcoholic beverages is among the inherent crimes, because the association of items such as alcoholic beverages with the norms and values of society and on the broader level of public security is such that in the law of every part of the free trade with it, including the import, export, purchase, sale, carriage and maintenance of the prohib- 
ited and the application of these regulations applies not only to businessmen, but also to all people of the country. Smuggling alcoholic beverages will not only lead to the withdrawal of a large part of the material capital of the community, but it is a serious threat to social, political, cultural, economic and national security by attacking the religious and cultural values and public security of the community. The phenomenon of smuggling, especially the smuggling of alcoholic beverages to Islamic countries with a noble culture like our country, has always been one of the most important and complex concerns of government, law enforcement and political officials in the last two decades.

The smuggling of alcoholic beverages is an issue that affects Iranian society and, in particular, Kurdistan province and the city of Ghorveh and this city always deal with this phenomenon and fight it. In this research, the impact of the use of anti-smuggling equipment and its effectiveness in the city of Ghorveh was investigated.

Ghorveh city is one of the most important cities of Kurdistan province and the center for many cross-country vehicles to other provinces and because of the smuggling of alcoholic beverages in the province of Kurdistan and sent to other provinces, the city of Ghorveh is one of the traffic areas of these people therefore, the aim of this study is to find the city of Ghorveh.

The present study was conducted with a quantitative and survey approach and a researcher made questionnaire in autumn of 2018. Validity and reliability of the research tool (questionnaire) were determined through face validity and Cronbach's alpha.

The statistical population of the study consisted of 20 colleagues and law enforcement personnel who were responsible and knowledgeable in the subject area of Ghorveh city and all of them were tried to complete the questionnaire. In this study, Spss and Excel software were used. The results indicated that most respondents were part of the Officer's questionnaire and their education was a bachelor's degree and respondents had a range of service lives ranging from 0 to over 20 years of age. In describing the research fields, the results showed that most respondents were distributed in the "large" and "very large" spectrum, which is mostly partly agreed with the items proposed. In other words, the majority of respondents believed that the law enforcement practices coping with the smuggling of alcoholic beverages in the city of Ghorveh had been effective in preventing this issue. Indeed, research indicates that the use of equipment in the fight against the smuggling of illegal and illegal goods, such as narcotics and alcoholic beverages, is an effective way.

The present study, considering the use of appropriate equipment in the fight against smuggling of alcoholic, concluded that; this is, of course, an effective and useful way to fight smuggling of alcoholic beverages. In other words, according to the results of this study, the use of appropriate equipment to fight smuggling of alcoholic beverages in the country and in particular in the city of Ghorveh, to the extent that is effective, is effective. According to the results, the appropriate equipment for combating and smuggling alcoholic beverages in the city of Ghorveh, respectively, of the answers provided by the respondents to the questions of the questionnaire are:

1- Use of modern and new car equipment

2- Using databases

3- Using the GPS system

4- Developing a style sheet for smugglers to executive units

5- Using an X-Ray device

6- Using information sources and contributors

7- Implementation of operational plans against the smuggling organization 
8- Conducting Staff Charters in Trafficking Cases

9- Use of temporary checkpoints

10-Develop annual planning for fighting units

11-Using Geographic Information System (GIS)

12- Provide anti-trafficking instructions

13-Using the office automation system instead of correspondence in expediting the delivery of plans, instructions, staff guidance, practices and practices, breaking news for liquor trafficking, etc. from toplevel and vice versa

14-Use of permanent and permanent checkpoints

\section{References}

Abdollah Jasbi, (1990), Book of Principles and Principles of Management, Azad Islamic University Press, pages 241 to 248.

Abdulmohammadi Amir, (2009), Study and study of social factors affecting smuggling in Iran, Quarterly Journal of Security and Police, No. 3, Second Year, Pages 207-179.

Ahmadi. Abdollah, (2003), Smuggling or economic anatomy, publishing rate.

Amir Hossein. Mehdi, (2014), Law Enforcement Administration Unrest in the 9th Islamic Consultative Assembly Elections in Doroud District Police Command, Quarterly Journal of Information and Security Studies, Vol. 4, No. 10, pp. 39-66.

Asgari Javad, (2014), The role of law enforcement in controlling the bad hijab phenomenon (Case study: District 2 of Tehran), Quarterly Journal of Information and Security Studies, Fourth Year, Number two, Successive, Eighth, pp. 142-117.

Ashrafi Joseph, (2007), Investigating the Practical Practices for Combating Smuggling of Alcoholic Goods from the Sardasht Frontier in 2006, Master Thesis for Crime Investigation, Police University, Faculty of Criminalistics.
Aslan Slams Abed, Deindredo. Saeed Aslani Slammers. Omid, (2015), Investigating the Social Factors Affecting Baneh's Boundary Traits on Trafficking in Goods (Sectors and Strategies), Journal of Social Psychology, seventh year, issue no., Pp. 56-33.

Daneshvar Gholamreza, (2010), Article Principles of Supervision and Control, Master of Science in Management, Academic Leaflet. Hairdresser Jamal, (2017), Law Enforcement Management Practices in the fight against smuggling of alcoholic beverages, Housing Economics Monthly, First Year, No. 3.

James C. Coleman, translated by Kianoush Hashemian, 1997, Book "Anomalous Psychology and New Life," published by al-Zahra University, Tehran.

Madani, Moghimi. Mehdi, (2018), Police Legal Laids at Police Inspection Stations, Encyclopedia of Social Sciences Quarterly, Tenth, No. 2.

Mohseni Tabrizi Alireza, Neypoor. Mohammad, Faridmehr Rahim, (2008), Factors Affecting the Smuggling of Arms and Alcoholic Beverages from the Pirjanshar District, Quarterly Journal of Police Management Studies, Third Year, No. 2, pp. 192-182.

Mustafa Nezhad Hassan, (2010), Management of Ethnic Crisis with the Police Approach, Zard Publishing House, Tehran.

Parsley Langroudi. Mohammad Jafar, (2007), Book of Terminology of Law, Eighteenth Edition, Ganj Danesh Publications.

Pitt, M. M, (1984), Smuggling and the Black Market for Foreign Exchange, Journal of International Economics, Volume 16, Issues 34, Pp. 243-257. https://doi.org/10.1016/S00221996(84)80003-3

Pitt, mark, 1981, Smuggling and price disparity, journal of international Economics, XI. https://doi.org/10.1016/0022-1996(81)90026-X

Rancid Hadi, the right friend. Ali Akbar, Salsali. Mahvash, Khoshdel Aria, Soleimani. Mohammad Ali, Bahrami Nasim, (2012), Sampling in Qualitative Research: A Guide to Beginning, Journal of the Army University of 
Medical Sciences, Islamic Republic of, Volume 10, Issue 3, 238-250.

Seyyed Hassan Vahdati Shobeiri, (1997), The book "Alcohol and its Products in Islamic Jurisprudence",Publishing House of the Islamic Propaganda Department of Qom Seminary, Qom.

Taliban Hussein, (2011), Alcoholic Threat Threat Threat, Detective Journal, Second Volume, Year 5, No 18, pp. 130-141

The pronoun Mohammad Reza, (2003), Men's Drinking - A Crime Against Women and Family, Journal of Strategic Women Studies, No. 20. https://doi.org/10.1007/s12118-003-1112-0 Trustworthy Ali, (2015), Implementation of the Law Enforcement Policies against Drug Sales, Journal of Counter Narcotics Studies, seventh year, No. 24 \& 25, pp. 45-37.

Vatankhah Hamid, (2013), an Investigation of the Pattern of Police Management in Prevention of Guilty Protest, Law Enforcement Administration Research Journal, No. 4.

Yavari Amir Hossein, Besharati manesh Mehdi, (2014), Law Enforcement Administration Unrest in the 9th Islamic Consultative Assembly Elections in Doroud Provincial Police Command, Journal of Information and Security Studies, Volume 4, Issue 10, Pages 39-66.

Yousefvand Javad Khani Saeed, (2013), A Survey on the Prevention of Trafficking in Goods by Police Approach, Journal of Information and Criminal Investigation, Vol. 8, No. 4 (Malcel, 32), pp. 113-160.

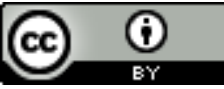

License information: This is an openaccess article distributed under the terms of the Creative Commons Attribution License, which permits unrestricted use, distribution, and reproduction in any medium, provided the original work is properly cited.

Article received on August 02, 2019.

Evaluated September 30, 2019.

Accepted on September 30, 2019.

Published on October 02, 2019.

How cite this article (ABNT):

MOHAMMADI, Reza; KAZEMI, Seyyed Sajjad. Investigating the impact of the use of security equipment in the confrontation with the arrival of alcoholic drinks "Case Study of Ghorveh City". Estação Científica (UNIFAP), Macapá, v. 9, n. 1, p. 119-132, Jan./ Mar. 2019. 